\title{
Permasalahan Guru Terkait Pengembangan Perangkat Pembelajaran RPP Model Inkuiri Terbimbing Materi Sistem Gerak Pada Tumbuhan Siswa Sekolah Menengah Pertama
}

\author{
Turini $^{1}$, Vandalita M.M. Rambitan*, Elsje Theodora Maasawet ${ }^{2}$ \\ Fakultas Keguruan dan Ilmu Pendidikan Magister Biologi \\ Universitas Mulawarman \\ Email: ibu.turini@gmail.com
}

\begin{abstract}
Abstrak
Permasalahan yang kerap terjadi adalah kurangnya kemampuan guru dalam hal mengembangkan perangkat pembelajaran RPP model inkuiri terbimbing di sekolah SMP terutama pada materi sistem gerak pada tumbuhan. Maka tujuan dari penelitian ini adalah mengetahui permasalahan apa saja yang dihadapi oleh guru pada saat mengembangkan pembelajaran RPP model inkuiri terbimbing. Metode penelitian ini adalah kuantitatif dengan pendekatan kualitatif. Teknik pengumpulan data pada penelitian ini adalah menggunakan instrument berisi komponen dari RPP yang akan disebarkan pada guru enam SMP (SMPN 1, 2, 3, 4, SMP YPM Tenggarong Seberang dan SMPN 5 Sebulu) Kabupaten Kutai Kartanegara. Populasi penelitian ini adalah seluruh guru SMP yang ada di kecamatan Tenggarong Seberang dan satu sekolah SMPN 5 kecamatan Sebulu, Kutai Kartanegara kemudian sampel penelitian ini berjumlah 15 orang guru dengan bidang keahlian (Biologi, Fisika dan Kimia). Penelitian ini merupakan analsisi kebutuhan untuk mengetahui kenyataan di lapangan yang berhubungan dengan proses pembelajaran yang selama ini dilaksanakan di Sekolah. Teknik analisis data menggunakan persentase \%. Hasil penelitian menunjukan bahwa kemampuan guru dalam mengembangkan perangkat RPP terkait Identitas sekolah 100\% guru paham akan dal tersebut, KI 100\% guru paham karena telah ditentukan dalam Silabus, Merumuskan KD 75\% guru tidak paham, Merumuskan Tujuan $87,5 \%$ guru tidak paham, Strategi pembelajaran 75\% guru tidak paham, Materi pembelajaran $75 \%$ guru tidak paham, sintaks pembelajarn $87,5 \%$ guru tidak paham dan evaluasi pembelajaran $87,5 \%$ guru tidak paham. Kurangnya pemahaman guru dalam mengembangkan perangkat RPP model inkuiri terbimbing mengakibatkan hasil belajar siswa menurun
\end{abstract}

Kata Kunci: RPP, Inkuiri terbimbing, Sistem Gerak Tumbuhan

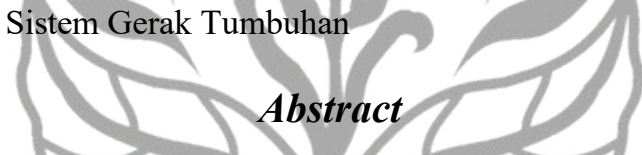

The problem that often happens is the lack of ability of teachers in developing learning inquiry guided RPP model in junior high school especially on the material of motion system in plants. So the purpose of this study is to find out what problems faced by teachers at the time of developing learning RPP guided inquiry model. This research method is quantitative with qualitative approach. Data collection technique in this research is using instrument containing component from RPP which will be disseminated to 6 teacher of SMP (SMPN 1,2, 3, 4, SMP YPM) in Tenggarong Seberang and SMPN 5 in Sebulu district of Kutai Kartanegara Regency. The population of this research is all teachers of junior high school in Tenggarong Seberang district Kutai Kartanegara regency Kutai Kartanegara Regency then the sample of this study amounted to 15 teachers with the field of expertise (Biology, Physics dan Chemistry). This study is an analysis of the need to know the reality in the field related to the learning process that has been implemented in the School. Data analysis techniques use percentage\%. The results showed that the ability of teachers in developing RPP tools related to school identity 100\% of teachers will understand it, KI 100\% of teachers understand because it has been determined in Syllabus, Formulate KD $75 \%$ of teachers do not understand, Formulate Objectives $87.5 \%$ of teachers do not understand, Learning strategy $75 \%$ of teachers do not understand, Learning materials $75 \%$ of teachers do not understand, learning syntax $87.5 \%$ of teachers do not understand and learning evaluation $87.5 \%$ of teachers do not understand. The inability of teachers in developing RPP device in guided inquiry model resulted in decreased student learning outcomes.

Keywords : RPP, Guided Inquiry, Plant Motion System

\section{Pendahuluan}

Pembaharuan pendidikan harus selalu dilakukan untuk meningkatkan kualitas pendidikan dan kualitas sumberdaya manusia semakin maningkat. Pendidikan adalah usaha sadar dan terencana untuk mewujudkan suasana belajar dan proses pembelajaran agar pesertadidik secara aktif mengembangkan potensi dirinya untuk memiliki kekuatan spiritual keagamaan, pengendalian diri, kepribadian, kecerdasan, akhlak mulia, serta keterampilan yang diperlukan dirinya, masyarakat, bangsa dan negara. (UU RI No 20 Tahun 2003) [1].

Kurikulum 2013 dikembangkan dengan alasan untuk melakukan, Penguatan pola pembelajaran yang berpusat pada peserta didik. Peserta didik harus memiliki pilihanpilihan terhadap materi yang dipelajari dan gaya belajarnya 
(learning style) untuk memiliki kompetensi yang sama; Penguatan pola pembelajaran interaktif (interaktif gurupeserta didik-masyarakat lingkungan alam, sumber/media lainnya); Penguatan pola pembelajaran secara jejaring (peserta didik dapat menimba ilmu dari siapa saja dan dari mana saja yang dapat dihubungi serta diperoleh melalui internet). Penguatan pembelajaran aktif-mencari (pembelajaran siswa aktif mencari semakin diperkuat dengan pendekatan pembelajaran saintifik). Penguatan pola belajar sendiri dan kelompok (berbasistim). Penguatan pembelajaran berbasis multimedia. Penguatan pola pembelajaran berbasis klasikal - misal dengan tetap memperhatikan pengembangan potensi khusus yang dimiliki setiap peserta didik; Penguatan pola pembelajaran ilmu pengetahuan jamak(multidisciplines); Penguatan pola pembelajaran kritis, [2].

Pembelajaran Biologi seharusnya menekankan pada pemberian pengalaman belajar langsung untuk mengembangkan kompetensi agar siswa memperoleh pemahaman yang lebih mendalam tentang dirinya sendiri dan alam sekitar. Sehingga dalam pembelajaran hendaknya menyediakan berbagai pengalaman belajar untuk memahami konsep dan proses Biologi, salah satu materi IPA biologi di sekolah menegah pertama iyalah system gerak pada tumbuhan dimana materi tersebut memerlukan pembuktian, dengan adanya pembuktian akan menambah pengalaman siswa pada saat proses pembelajaran berlangsung [3].

Namun bertolak belakang dengan harapan yang telah dikemukan diatas permasalahan yang kerap terjadi adalah kurangnya pemahaman guru dalam mengembangkan perangkat pembelajaran yang sesuai dengan materi dan tagihan KI dan KD dari kurikulum 2013. Hal itu disebabkan kurangnya literatur dan referensi guru terkait perangkat dan model yang sesuai dengan materi IPA Biologi yang diajarkan di SMP. Hal itu akan mengakibatkan menurunya hasil belajar siswa baik kognitif, afektif dan psikomotorik, Maka sangat penting seorang guru menciptakan pemebelajaran yang aktif dan menarik bagi siswa.

Ditinjau dari kurikulum 2013, pembelajaran IPA Biologi di SMP yang berkembang secara dinamis perlu adanya pendekatan saintifik (scientific approach) dan salah satunya adalah mengunakan model inkuiri. Menurut (Ronald, 1998) Inquiry : Learning from the Past with an Eye on the Future mengungkapkan bahwa inkuiri terbimbing masih memegang peranan guru dalam memilih materi atau bahasan, pertanyaan dan menyediakan materi, akan tetapi siswa diharuskan untuk mendesain atau merancang penyelidikan, menganalisa hasil sampai kepada kesimpulan [4]. Untuk menerapkan model pembelajaran inkuiri terbimbing perlunya seorang guru yang kratif dalam mengembangkan perangkat pembelajaran dengan langkahlangkah inkuiri terbimbing RPP. Dimana perangkat pembelajaran yang dikembangkan oleh guru diharapkan mampu meningkatkan hasil belajar siswa dan memberikan pengalaman belajar kepada siswa terkait materi yang diajarkan.

Perlunya suasana belajar yang menyenangkan dan memberikan pengalaman bagi siswa saat proses pembelajaran IPA Biologi berlangsung, terutama bagi siswa SMP. Tingginya rasa ingin tahu pada siswa SMP akan sangat membantu jika proses belajar mengajar menggunakan model Inkuiri terbimbing sehingga siswa-siswi dapat belajar dari lingkungan dan memahami setiap peristiwa alam yang terjadi dilingkungan sekitarnya [5]. Dari penjelasan diatas maka penelitian ini bertujuan untuk mengetahui kendala yang dihadapi oleh guru selama ini pada saat mengembangkan perangkat pembelajaran inkuiri terbimbing pada materi sistem gerak pada tumbuhan.

Berdasarkan latar belakang diatas maka rumusan masalah penelitian ini adalah permasalahan apa saja yang dihadapi oleh guru pada saat mengembangkan perangkat Pembelajaran RPP model Inkuiri terbimbing materi sistem gerak pada tumbuhan.

\section{Metode Penelitian}

Jenis penelitian ini adalah kuantitatif dengan pendekatan kualitatif. Teknik pengumpulan data pada penelitian ini adalah menggunakan instrument berisi komponen dari RPP yang akan disebarkan pada guru enam SMP (SMPN 1, 2, 3, 4, SMP YPM) di kecamatan Tenggarong Seberang dan SMPN 5 Kecamatan Sebulu Kabupaten Kutai Kartanegara. Populasi penelitian ini adalah seluruh guru SMP yang ada di kecamatan Tenggarong Seberang dan kecamatan Sebulu Kabupaten Kutai Kartanegara kemudian sampel penelitian ini berjumlah 15 orang guru dengan bidang keahlian (Biologi, Fisika dan Kimia). Penelitian ini merupakan analsisi kebutuhan untuk mengetahui kenyataan di lapangan yang berhubungan dengan proses pembelajaran yang selama ini dilaksanakan di Sekolah. Teknik analisis data menggunakan persentase :

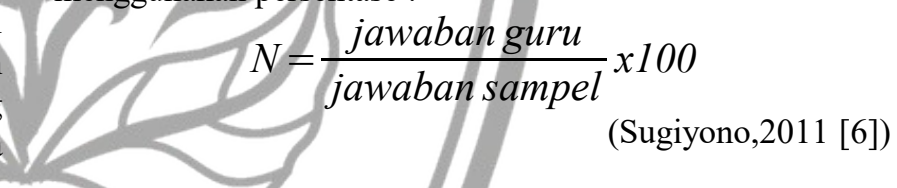
Hasil dan Pembahasan

- Penelitian yáng telah dilakukan di SMP kecamatan Tenggarong Seberang dan Kecamatan sebulu, Kabupaten Kutai Kartanegaramendapatkan hasil yang telah dituangkan dalam Table 1. Penelitian yang dilakukan disekolah SMPN 2 Tenggarong Seberang Kabupaten Kutai Kartanegara menujukkan bahwa banyak permasalahan yang dihadapi oleh guru IPA biologi dalam mengembangkan perangkat pembelajaran (RPP). Dari 10 komponen (RPP) kurikulum 2013 banyak guru yang belum memahami hal cara merumuskan dan menentukan model pembelajaran sesuai kebutuhan siswa dan kesesuaian dengan materi yang akan diajarkan oleh guru. Penelitian ini lebih ditujukan pada guru IPA untuk mengetahui permasaslahan apa saja yang dihadapi pada saat mengembangkan perangkat RPP model inkuiri terbimbing sehingga dapat ditemukan solusi yang tepat untuk mengatasi permasalahan tersebut. [7]

Pada Table 1. Terlihat jelas bahwa beberapa point dari komponen RPP berada pada komponen tidak paham, kurang paham dan paham. Sementara ada dua point $100 \%$ guru berada pada kategori sangat paham, misalnya komponen Identitas sekolah dan Kompetensi inti. Kedua point tersebut kita ketahui bahwa sudah ada di silabus dan telah ditetapkan 
oleh kementrian pendidikan sesuai dengan tagihan kurikulum. Sedangkan 8 komponen lainnya rata-rata berada pada kategori "tidak paham".

Tabel 1. Hasil penelitian terkait permaslaahan yang dihadapi oleh guru dalam mengembangkan perangkat

\begin{tabular}{|c|l|l|l|l|l|}
\hline \multirow{2}{*}{ No } & \multirow{2}{*}{$\begin{array}{l}\text { Komponen RPP yang } \\
\text { menjadi kendala guru }\end{array}$} & $\begin{array}{c}\text { Tidak } \\
\text { paham }\end{array}$ & $\begin{array}{l}\text { Kurang } \\
\text { paham }\end{array}$ & Paham & $\begin{array}{l}\text { Sangat } \\
\text { paham }\end{array}$ \\
\hline 1 & Identitas Sekolah & & & $100 \%$ \\
\hline 2 & Kompetensi Inti & $75 \%$ & $25 \%$ & & $100 \%$ \\
\hline 3 & $\begin{array}{l}\text { Merumuskan } \\
\text { Kompetensi Dasar }\end{array}$ & $\begin{array}{l}\text { Merumuskan tujuan } \\
\text { pembelajaran }\end{array}$ & $87,5 \%$ & $12,5 \%$ & \\
\hline 5 & $\begin{array}{l}\text { Strategi pembelajaran } \\
\text { (inkuiri, terbimbing, } \\
\text { praktikum) }\end{array}$ & $87,5 \%$ & $12,5 \%$ & & \\
\hline 6 & $\begin{array}{l}\text { Materi pembelajaran } \\
\text { (sistem gerak pada } \\
\text { tumbuhan) }\end{array}$ & $75 \%$ & $25 \%$ & & \\
\hline 7 & Sintaks pembelajaran & $87,5 \%$ & $12,5 \%$ & \\
\hline 8 & Evaluasi pembelajaran & $87,5 \%$ & $12,5 \%$ & \\
\hline 9 & $\begin{array}{l}\text { Sumber belajar } \\
75 \%\end{array}$ & 25.00 & \\
\hline
\end{tabular}

Merumuskan kompetensi dasar $75 \%$ guru berada pada kategori tidak paham dan $25 \%$ guru pada kategori kurang paham hal itu menandakan bahwa ketidak mampuan guru mengkreat/menurunkan rumusan dari Kompetensi inti pada silabus dan disesuaikan dengan taguhan dari materi yang akan diajarkan pada siswa terkait sistem gerak pada tumbuhan memlalui model inkuiri terbimbing. Kemampuan merumuskan tujuan pembelajaran $87,5 \%$ guru berada pada kategori tidak paham dan 12,5\% guru kurang paham dalam merumuskan tujuan pembelajaran, berdasarkan hasil pernyataan diinstrumen dapat disimpulkan bahwa banyak guru yang tidak dapat merumuskan tujuan pembelajaran yang tepat dengan materi yang akan diajarkan dan menyesuaikan dengan model pembelajaran inkuiri terbimbing. Tujuan pembelajaran sangat penting dijadikan sebagai patokan keberhasilan suatu pembelajaran sehingga guru dituntut untuk merumuskan tujuan pembelajaran yang sesuai dengan materi pembelajaran.

Penyusunan materi pembelajaran $75 \%$ guru berada pada kategori tidak paham dan $25 \%$ guru berada pada kategori kurang pahamsehingga selama ini hanya menggunakan buku paket yang disediakan di sekolah tersebut. Kurangnya materi atau suplement materi yang tersedia mengakibatkan siswa kurang mampu dalam mengikuti pembelajaran terutama dalam materi yang memerlukan pembuktian. Guru yang kreatif dalam menyusun handout akan memberikan informasi baru dan kemudahan kepada siswa dalam mengikuti proses pembelajaran, sejalan dengan pernyataan Pannen (2011) bahwa materi ajar yang mudah dipahami dan berisi informasi terbaru sangat dibutuhkan dalam proses pembelajaran agar siswa mendapatkan informasi terbaru [8].
Pemilihan model pembelajaran yang sesuai dengan materi yang akan disampaikan kebanyakan guru kurang paham, salah satu model pembelajaran yang dibutuhkan dalam proses belajar biologi adalah model pembelajaran inkuiri terbimbing, model ini memiliki sintaks yang menuntut praktikum/pembuktian pada suatu perkara, tetapi pada realitanyan $87,5 \%$ guru tidak memahami dan $12,5 \%$ guru kurang paham bagaimana sintaks dari inkuiri terbimbing tersebut dan cara mengaplikasikan didalam kelas. Dari hasil penelitian tersebut terlihat sangat miris, karena kurangnya kemampuan guru dalam hal mengelolah pembelajaran disekolah. Hal tersebutlah yang mengakibatkan menurunnya hasil belajar siswa dan semangat siswa menjadi berkurang.

Terkait penyusunan evaluasi belajar terdapat $87,5 \%$ tidak paham dan $12,5 \%$ guru kurang paham hal itu disebabkan karena ketidak mampuan dalam menyesuaikan model pembelajaran dan menyusun sintask pembelajaran pada materi yang akan diajarkan. Jika seorang guru paham akan model dan menyusun sintaks pembelajaran makan guru akan paham apa yang harus dilakukan pada saat evaluasi pembelajaran. Evaluasi pembelajaran merupakan alat ukur melihat keberhasilakn siswa pada saat akhir pembelajaran. Evaluasi pembelajaran ini tercakup dari semua aspek (Kognitif, Afektif dan Psikomotorik) ketiga aspek ini tidak bisa dipisahkan jika ingin melihat keberhasilan siswa secara komplit. [9]

Pemilihan sumber belajar $75 \%$ guru tidak paham dan $25 \%$ guru kurang paham dalam menuliskan sumber belajar, sehingga banyak guru yang hanya tau mengcopy paste hasil karya orang lain tanpa mengkutip nama penulis sehingga akan mengakibatkan plagiat. Perlu diketahui bahwa pada zaman teknologi sekarang ini sangat diperhatikan setiap tulisan yang dikutip untuk mencantumkan sumber utamannya. Untuk sumber belajar sangat diperlukan yang terbaru karena jimu terus berkembang.

\section{Kesimpulan dan Saran}

Berdasarkan penelitian yang telah dilakukan maka dapat disimpulkan bahwa kemampuan guru dalam mengembangkan perangkat RPP model inkuiri terbimbing seacara merata $75 \%$ guru tidak paham dan $25 \%$ kurang paham. Jika dilihat dari setiap kompenen dari RPP yang dilmulai dari Identitas sekolah $100 \%$ guru paham akan dal tersebut, KI $100 \%$ guru paham karena telah ditentukan dalam Silabus, Merumuskan KD 75\% guru tidak paham, Merumuskan Tujuan $87,5 \%$ guru tidak paham, Strategi pembelajaran $75 \%$ guru tidak paham, Materi pembelajaran $75 \%$ guru tidak paham, sintaks pembelajarn $87,5 \%$ guru tidak paham dan evaluasi pembelajaran $87,5 \%$ guru tidak paham. Ketidakmampuan guru dalam mengembangkan perangkat RPP mengakibatkan hasil belajar siswa menurun.

\section{Daftar Pustaka}

[1] Depdikbud. (2013). Kurikulum, Standar Kompetensi Mata Pelajaran Biologi Sekolah Menengah Atas. Jakarta.

[2] Science, N. A. (2000). Inquiry and national science educational standars. Wasington: National Academic. Press.

[3] Bell, B. H. (2008). The Many Level Inquiry. Washington. 
[4] Ronald, B. (1998). Learning From the past with an eye on the future. Linclon: University Of Nebraska.

[5] Dahar. (1989). Teori-Teori elajar. Jakarta: Erlangga.

[6] Sugiyono. (2014). Statistik Pengembangan. Jakarta: Erlangga.

[7] Priyono \& Titik Sayekti.2010.Ilmu pengetahuan alam untuk SMP. Jakarta:Kementrian Pendidikan Nasional

[8] Pannen.2011.penulisan bahan ajar, pusat antar universitas untuk meningkatkan dan pengembangan aktivitas instruksionaldirektorat jendral pendidikan tinggi,Jakarta : Dapertemen pendidikan Nasional

[9] Sukardi, H. M. 2008. Evaluasi Pendidikan Prinsip dan Operasionalnya.Yogyakarta:Bumi Askara

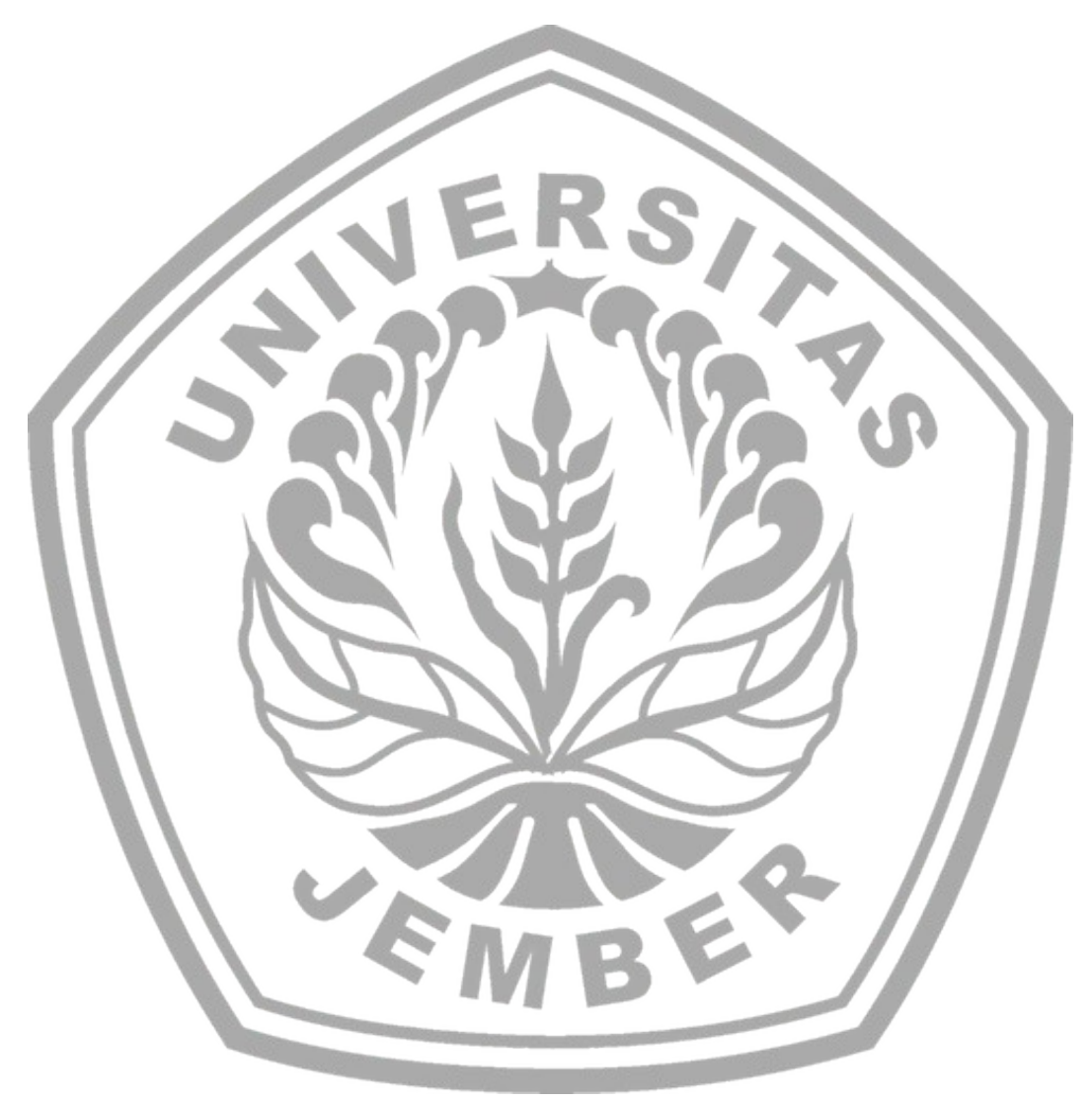

